\title{
Axiological Approach in The Development of Communicative Competences in University Students
}

\author{
Oskar Yakovlevich Goykhman ${ }^{1 *}$, Liubov Markovna Goncharova ${ }^{1,2}$, Ella Anatolyevna \\ Kitanina $^{2}$ and Tatyana Vyacheslavovna Nesterova ${ }^{2}$ \\ ${ }^{1}$ Russian New University, Department of Service and Business Communications, Moscow, Russia \\ ${ }^{2}$ Pushkin State Russian Language Institute, Department of General and Russian Linguistics, Moscow, \\ Russia
}

\begin{abstract}
The article discusses the possibility of the development of axiological competences in university students in the process of teaching language-related disciplines within the world educational space. The problem of the development of communicative competences is relevant in the modern educational environment; it determines the purpose of the study: to analyze the survey results illustrating the attitude of students to the value of communication in society. During the research, linguistic and axiological parameters, defined by students as linguistic and communicative values, were identified, which makes it possible to talk about modern trends in education. Particular attention is paid to the value categories of the Russian language as the basis for national and cultural orientation, successful communication, intellectual development of people and formation of their linguistic personalities. The authors regard the axiological approach in the development of the student's communicative competences as a fundamentally structured vision of the world through the prism of value orientation, which in the practice of cognition allows developing competences based on the cognitive needs and communicative intentions of students.
\end{abstract}

\section{Introduction}

Today a new system of values and new educational goals have appeared in the global educational process. The study of universal and cultural values is put in key positions. The world educational space unites national educational systems of various types and levels, significantly differing in philosophical and cultural traditions, the level of goals and objectives and their quality. Therefore, one should consider the modern world educational space to be an emerging single organism, provided that global trends are present in each educational system and the diversity of national cultures is preserved. "Culture can be considered to be a system of value orientations, which is general and universal for a society

\footnotetext{
* Corresponding author: aan1234569@yandex.ru
} 
(ethnos, nation) <..> It influences the perception, thinking, behaviour of all members of society and determines their belonging to this society" [1, p. 99].

For the linguistic and cultural concept and within the conceptual and cultural direction, new approaches to the concepts of "educational space" and "educational environment" have been formed. Educational space is an important socio-cultural characteristic of society. The development of society is multidimensional, but society itself and all its specific manifestations are generated and determined by individuals. The evolution of educational space reflects the specific features, main stages and patterns of human history.

It should be noted that the term "information environment" in the context of educational institutions comprises a set of educational information resources, including digital technologies. However, the concept of the learning environment, in our opinion, suggests the interconnection of conditions that ensure the education of the students, their spiritual growth, development as human individuals, and, therefore, the formation of new communicative competences. They include the axiological aspect, which is especially important in the process of teaching Humanities, in particular, in language- and speech-related disciplines, because students' understanding of values and cultural and speech traditions, as well as selfawareness as native speakers and culture-bearers, are formed.

\section{Methods}

The axiological aspect in teaching speech-related disciplines is not distinguished by either educational standards or developers or methodologists, although it is often present implicitly in the objectives of the learning process. Thus, I.A. Zimnyaya defines communicative competence as "mastering of complex communicative skills and abilities; the formation of adequate skills in new social structures; knowledge of cultural norms and restrictions in communication; knowledge of customs, traditions, etiquette of communication; decency and manners. It is a guide in the communicative means, inherent to the national and social class mentality, mastering of the role-playing within of the profession" [2, pp. 13-14]. A.V. Khutorskoy also points in his works to the importance of mastering of communication skills in a multicultural, multi-ethnic and multi-religious society, based on knowledge of the historical roots and traditions of various national communities and social groups [3].

This encourages us to research the identification, understanding and management of the development of the axiological components of the communicative competences in university students, which can be implemented in the following areas of work:

- resorting to the living language of the modern era with attention to the features of the representation of axiological meanings in texts/discourses of various areas of communication;

- text analysis from the point of view of its semantic value and cultural concepts;

- discovering of value potential in the study of vocabulary, grammar, stylistics, speech culture, etc.;

- mastering the methods of scientific communication in the modern multicultural educational environment by university students, taking into account the semantic value of national-ethnic cultural concepts.

The practical side of the problem lies in the features of the implementation of the idea of perception and reflection of cultural meanings associated with the Russian language. A constructively built activity will undoubtedly make it possible to obtain a positive result, which is a values-based attitude to the Russian language. To do this, one should approach the problem from the point of view of competent goal-setting, text-oriented teaching and students' worldviews. 


\section{Results}

The axiological component of communicative competence means teaching students the language and encouraging their understanding of linguistic and axiological realia, values and continuity, mindset to the preservation of cultural and speech traditions and etiquette norms.

In recent years, in methodological science and pedagogical practice, there has been an active process of the search for the best ways, methods, techniques and means of forming a values-based attitude to the language, primarily, as to a mother tongue.

We surveyed students to study the values that they distinguish in the process of studying the discipline "Russian language and culture of speech" according to the following aspects:

1 . What values should be strictly observed in verbal communication?

2. Which of them are regularly violated in modern communication? In what situations does this happen?

3. What do you consider the most valuable in communication between a teacher and a student in the learning process?

4. What values are prioritized for you when choosing the topic of your scientific work at the university?

The results obtained from the survey, conducted among 200 people, showed that students' assessment of linguistic and communicative values, considered from the point of view of national culture, is mainly determined not by the observance of linguistic norms or by the range of vocabulary, but by communicative parameters, such as mutual respect, respect for other people's traditions and customs, politeness, subordination, correct estimating of the opponent (age, position), tolerance, tactfulness, delicacy (Fig. 1).

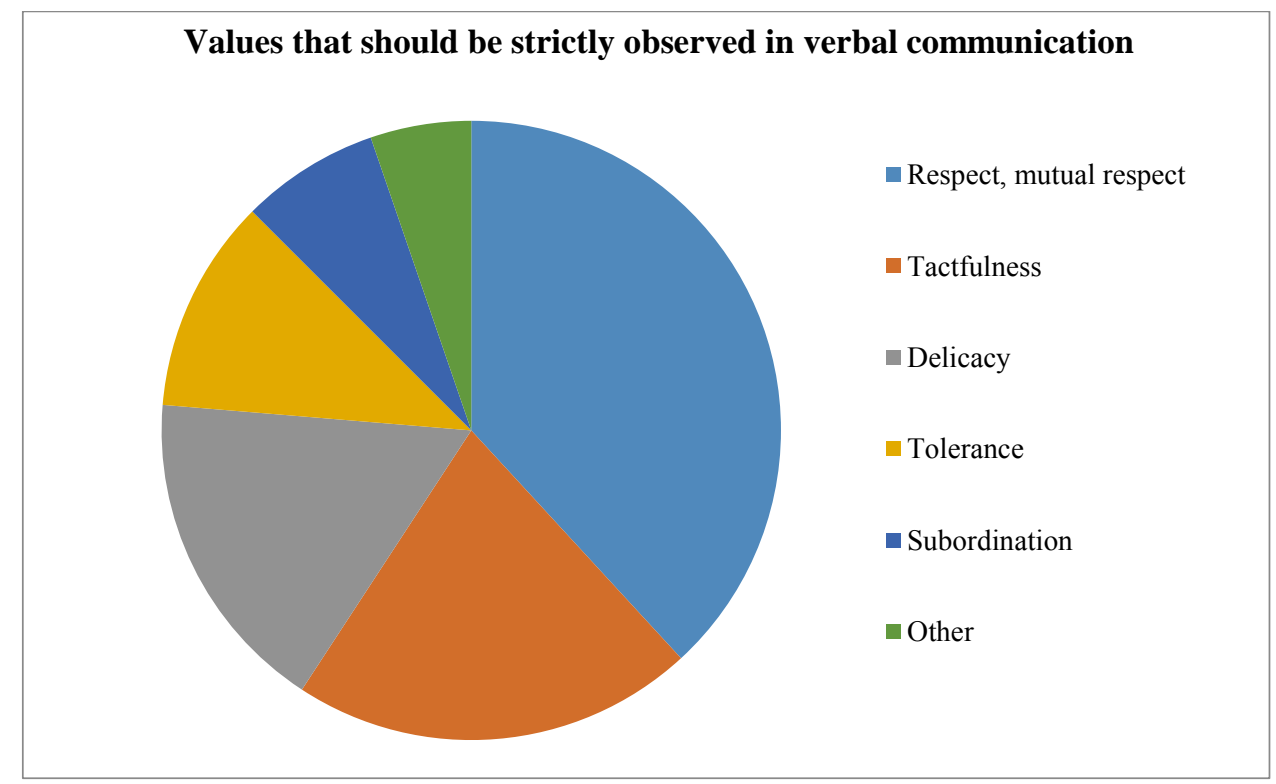

Fig. 1. Results of the survey

Among the most often recorded violations in modern communication, students mentioned lack of politeness and tactfulness towards the interlocutor, lack of subordination, intrusion and aggression in the commercial sphere, inappropriate jokes, frequent violation of personal boundaries, as well as disrespect for a partner (Fig. 2). 


\section{Values that are regularly violated in modern communication}

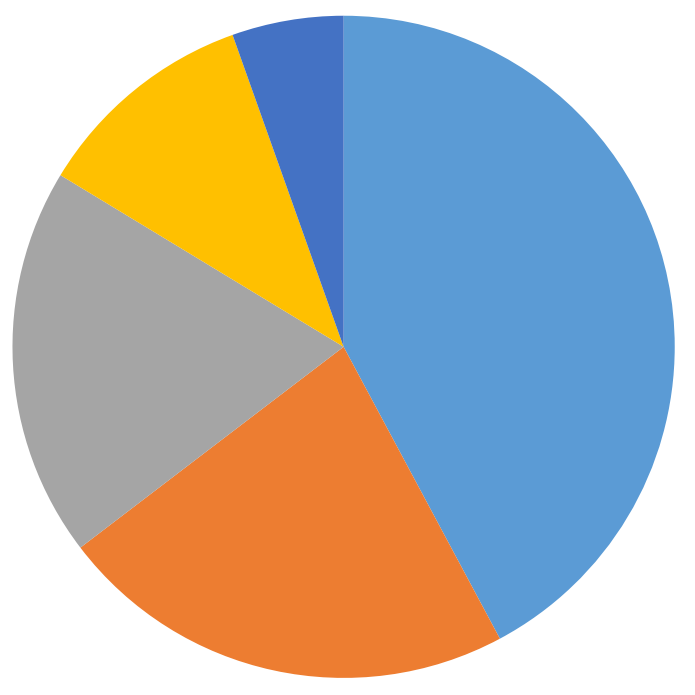

- Lack of politeness and tactfulness towards the interlocutor

- Lack of subordination

Inappropriate jokes

Aggression

- Other

Fig. 2. Results of the survey

Besides, the following data were obtained on the last two questions. The most valuable aspect in the communication between a teacher and a student in the learning process is mutual respect, clear boundaries of subordination, but at the same time freedom, humanity, tactfulness, concern for each other's interests, mutual understanding; ability to convey material interestingly and understandably. The following values were listed as prioritized when choosing the topic of scientific work at the university: interest in the topic, correspondence of the topic to the research vector set by the teacher, reliance on personal interests, the importance of the chosen topic in society, the desire to evolve in the scientific direction and connection with the future profession.

Thus, the overview of values, defined by the students' vision, reinforces the importance of the educational component of the language and the role of the teacher in the formation of the linguistic world-image, including taking into account multicultural realia in the educational environment of a modern university. According to L.S. Vygotsky, "in fact, direct teaching of concepts is impossible and pedagogically fruitless", "following this path, the teacher usually does not achieve anything but a superficial, even empty learning of words, naked verbalism that simulates and imitates the existence of relevant concepts among students, but in effect, covering up emptiness" [4, pp. 188].

\section{Discussion}

The axiological approach to the process of teaching Humanities is determined not only and not so much by memorizing rules or texts, but by forming among students the understanding of the value of obtained knowledge, inheriting the speech, cultural, moral and ethical traditions of the nation. It is also a necessary element of humanist education, in the centre of the system of which is a person entering the world of cultural values, developing spiritually, morally and intellectually. Starting from the 19th century, in the 20th century, this approach was promoted by outstanding Russian educators (F.I. Buslaev, K.D. Ushinsky and others). Today, in the aspect of the values-based approach, there are several ongoing studies: V.V. Kotlyarova [5], Kotlyarova et al. [6], T.N. Volkova [7], G.M. Kulaeva [8], A.D. Deikina [9]. 
The importance of this direction is emphasized by the conferences ("Axiological aspects of the teaching methods of the Russian language (professional and general educational levels [10])" and others.

According to A.D. Deikina, "strategies associated with the personal interaction of a teacher and students are chosen by a professional teacher, based on opportunities to actualize the intellectual potential of a person, to provide spiritual and moral maturation of a person, to fill the educational process with personally significant, cultural and life content" [9].

The value categories of the Russian language, perceived and understood by students in the learning process, become the basis of the national and cultural orientation, successful communication, intellectual development of people and formation of their linguistic personalities.

\section{Conclusion}

Cognitive stereotypes act as an instrument of the impact of the world model on the speech behaviour of an individual, which, through the actual presentation of socially sanctioned objective needs, can provide a stimulating typified effect on a person's consciousness. In practice, this effect manifests itself in the fact that, relying on a particular system of cognitive stereotypes, specific for each sphere, an individual masters a certain tradition that determines the fundamental structures of his vision of the world. In its turn, it forms his values, and in the practice of cognition, it is found in his cognitive needs and communicative intentions. However, the influence of conceptual systems on a person's behaviour through stereotypes is not limited. Ensuring the concerted actions of members of a community, such systems determine significantly types of the actions of each member, imposing a set of operations and rules for their use.

It is necessary to underline the importance of the interaction and cooperation of students, as well as the speech objective for organizing communicative learning, which includes the formation of a communicative concept, that is, internal readiness and ability for speech interaction.

This work was financially supported by the Russian Foundation for Basic Research (RFBR) within the science project No. 19-012-00609 "Modern Russian axiosphere: semantic and pragmatic transformation of the Russian cultural code".

\section{References}

1. I.N. Khokhlova. Intercultural communication. Concept, levels, strategies. Relevant problems of philology, in Proceedings of the International Scientific Conference, October 2012, Perm, Russia (2012)

2. I.A. Zimnaya, Pedagogical psychology: textbook (Logos, Moscow, 2004)

3. A.V. Khutorskoy, Bul Inst Human Ed 1 (2011)

4. L.S. Vygotsky, Collected Works: in 6 volumes. Vol. 2: Problems of General Psychology. (Pedagogy, Moscow, 1982)

5. V.V. Kotlyarova, Values: traditions and the axiological paradigm of modernity (GOU VPO "YURGUES", Shakhty, 2009)

6. V. V. Kotlyarova, A. M. Roudenko, M. M. Shubina, Y. A. Shestakov, Medit J Social Sci 6(3), 477-482 (2015)

7. T.N. Volkova, Education of a person of culture by means of language and art in the process of humanitarian education (Shuya, 2007) 
8. G.M. Kulaeva, The aesthetic ideal in the system of forming the value attitude of students to the Russian language: Ph.D. Thesis (Moscow, 2008)

9. A.D. Deikina, The formation of a linguistic personality with a value outlook on the Russian language: methodological problems of teaching the Russian language (Agentstvo Pressa LLC, Moscow; Orenburg, 2009)

10. A.D. Deikina, A.P. Yeremeyeva, L.A. Khodyakova, V.D. Yanchenko, Axiological aspects of the methodology of teaching the Russian language (professional and general educational levels), in Proceedings of the International Scientific-Practical Conference, 19-20 March 2009, Moscow, Russia (2009) 